\title{
A MODINHA COMO EXPRESSÃO NACIONAL DO SÉCULO XIX: DESMISTIFICANDO A AURA DE GÊNIO DO PADRE JOSÉ MAURÍCIO NUNES GARCIA
}

\section{THE "MODINHA" AS AN EXPRESSION OF THE XIXth CENTURY. DEMYSTIFYING THE PRIEST GARCIA'S GENIUS AURA}

\author{
Pedro Razzante Vaccari \\ Universidade Estadual Paulista \\ pedrovaccari@hotmail.com
}

\section{Resumo}

A figura do gênio romântico, atormentado e incompreendido, que morre na miséria, tem acompanhado o fluxo de mistificação histórica desde o século XVIII, na figura de Mozart. Transladado para os trópicos, esse personagem foi personificado em José Maurício Nunes Garcia, compositor negro da Corte de D. João VI no Brasil, que teria Marcos Portugal como rival e antípoda - o Salieri de Portugal/Brasil. Por meio de uma pesquisa que analisou todos os Jornais de Modinha publicados em Lisboa de 1792 a 1796, e as Modinhas Imperiais que vieram a prelo pelas mãos de Mário de Andrade em 1930, pudemos perceber, entretanto, que o gênero modinha, cultivado por José Maurício em pelo menos quatro peças sobreviventes, possui elos motívicos que podem caracterizá-lo como pertencente a uma nacionalização incipiente da música brasileira. A partir dessa premissa foi possivel traçar um perfil do Padre que desmistifica a aura do gênio, já que suas modinhas, em específico "Marilia, si me não amas...", trazem elementos que remontam à tradição popular oral brasileira. A Modinha, gênero que ressoaria em suas próprias missas para constituir uma brasilidade em música, não seria antes um gênero aglutinador de influências folclóricas e populares urbanas, e o fato de José Maurício compor nesse estilo não o aproximaria das correntes tradicionais de retórica neo-trovadoresca?

Palavras-chave: Modinha; gênio romântico; Padre José Maurício Nunes Garcia; popular-tradicional.

Universidade Estadual Paulista - Unesp. https://orcid.org/0000-0002-2492-9362. 


\begin{abstract}
The establishment of the romantic genius, full of anguish and misunderstood, who dies in misery, has followed the flow of historical mystification since the 18th century, in the figure of Mozart. Transferred to the tropics, this character was personified in Father José Mauricio Nunes Carcia, black composer of the Court of D. João VI in Brazil, who would have Marcos Portugal as his rival and antipode - the true Salieri of Portugal / Brazil. Through our research, that analyzed all the Modinha Newspapers published in Lisbon from 1792 to 1796, and the Imperial Modinhas that were published by Mário de Andrade in 1930, one can see, furthermore, that the genre modinha, cultivated by José Mauricio in at least four surviving pieces, has motivic links that can characterize him as belonging to an incipient nationalization of Brazilian music. Based on this argument, it was possible to draw a profile of the Father that demystifies the aura of genius, since his modinhas, specifically "Marilia, si me não amas...", bring characters that remind us the popular Brazilian oral tradition. Modinha, a song that would resonate in its own masses to constitute a Brazilianness in music, would not be a genre that brings together urban folk and popular influences, and the fact that José Maurício composed in this style would not bring him closer to the traditional currents of neo-troubadour rhetoric?
\end{abstract}

Keywords: Modinha; romantic genius; Padre José Maurício Nunes Carcia; traditional popular. 


\section{Introdução}

culto ao chamado "gênio romântico" nas Artes foi um impulso tomado a partir do lluminismo, com a ascensão da burguesia e consequente decadência da Aristocracia e da Monarquia, na Europa Ocidental dos séculos XVII e XVIII. Amparados pelo embasamento científico empírico e com o baluarte da razão, os então denominados iluministas eram intelectuais a serviço da propagação dos ideais que levariam à Revolução Francesa (1789-99), que destituiria a Monarquia Absolutista da França - carregando, em seguida, diversas outras monarquias absolutistas europeias. $\bigcirc$ pensamento iluminista, ilustrado e racional que dominou esses teóricos setecentistas e oitocentistas, no entanto, não considerava a totalidade dos fenômenos culturais, interpretando muitas vezes a cultura e a própria arte como tendências ou movimentos isolados e individuais. Como salienta Márcio Suzuki:

Privados da perspectiva do todo e, por isso, condenados a um pensamento especializado e maquinal, é assim que os pensadores iluministas concebem o coroamento daquilo que chamam de cultura, como se a formação da humanidade significasse hipertrofia da racionalidade e incremento das habilidades mecânicas (SUZUKI, 1998, p.63).

Essa contextualização permitiria que fosse traçado o perfil do gênio romântico nas Artes - solitário e psicologicamente conturbado, condenado e vitimizado pela elite econômica e intelectual de seu país. A figura do gênio incompreendido talvez nunca tenha tomado proporções como com o que vimos com a mítica imagem disseminada do compositor alemão Ludwig Van Beethoven (1770-1827). Isolado do meio em que nasceu, da sociedade e de sua própria cultura, o gênio era alçado ao patamar invicto de glória inatingível que nada devia ao seu povo ou à sua nação.

Atrelada inicialmente ao estigma do gênio romântico, a cultura foi, aos poucos, transmudando-se com o passar dos séculos, e a perspectiva solitária do artista genial foi cedendo à valorização de outros protótipos culturais, e mesmo a produção romântica do século XIX passou a ser inserida dentro de seu contexto sócio-histórico, antropológico e cultural. 
Desde formas avançadas de nacionalismo e de concepções românticas de gênio criativo, até os estudos sobre as relações intrínsecas nos séculos XX e XXI, entre a cultura de massas, a economia e a politica, as definições de cultura têm se ampliado significativamente (CLASER, 2011, p.23-4).

Essas definições e as metodologias para se estudar a cultura ganharam nova problemática a partir do final do século XIX, quando começaram a despontar pesquisas que buscavam unir a Etnologia e a Musicologia. Particularmente na Alemanha e nos EUA, esses incipientes estudos - nas décadas de 1880 e 1890, segundo Alan Merriam (1964), pareciam ter encontrado uma fusão satisfatória entre as duas áreas do conhecimento. A Etnomusicologia, com a Antropologia enquanto método, objetivava transferir o foco das investigações musicológicas, da música como fenômeno isolado para o estudo do som musical em sua forma holística - como produto da humanidade em primeiro lugar. Sobre a Etnomusicologia, escrevia Alan Merriam:

Esta natureza híbrida da área é marcada por sua literatura, onde enquanto alguns acadêmicos escrevem tecnicamente sobre a estrutura do som musical como um sistema em si mesmo, outros (etnomusicólogos) escolhem tratar a música como uma parte funcional da cultura humana e como uma parte integrante de um todo maior (MERRIAM, 1964, p.3). ${ }^{2}$

Esse ponto de vista passou a ser abordado em diferentes pesquisas etnomusicólogicas. Concebida inicialmente como uma área que estudaria a música periférica, a não-ocidental, a folclórica e a popular urbana e rural, gradualmente começou a ser empregada para toda e qualquer investigação sobre a música inserida em seu contexto social, político, cultural e histórico, conforme John Blacking (1973) em How musical is man.

No Brasil viria a surgir, ainda que de forma incipiente, no pensamento de Mário de Andrade (1893-1945), um dos principais articuladores

2 "This dual nature of the field is marked by its literature, for where one scholar writes technically upon the structure of music sound as a system in itself, another chooses to treat music as a functioning part of human culture and as an integral part of a wider whole" (tradução minha). 
do Movimento Modernista. Em Ensaio sobre a música brasileira, de 1928, por exemplo, defendia o valor de uma arte coletiva, oposta ao diletantismo obscurantista que verificara na música de concerto de então. Segundo o autor, "Os efeitos do individualismo artístico no geral são destrutivos" (ANDRADE, 2006 [ 1928], p. 15). Ainda que em seguida Andrade se posicione a favor da formação de espécies de gênios brasileiros, aqui já se verifica uma tendência a procurar a música coletiva, estruturada em conjunto, a música oral, passada de gerações a gerações, em detrimento da imagem consagrada do gênio romanesco atormentado.

As correntes ulteriores da Musicologia trariam luz ao aspecto metodológico da área: tomavam-se emprestados à Antropologia os métodos, entre eles a própria pesquisa de campo. Através dela seria possivel anotar, transcrever a música e travar contato com as culturas pesquisadas, método que é comumente empregado na Antropologia (OLIVEIRA PINTO, 200 I, p.250).

Esse enfoque, portanto, trouxe à Ełnomusicologia a prática empírica da pesquisa de campo, e ao investigar as culturas locais, periféricas, folclóricas e populares tradicionais, foi, aos poucos, formando os materiais que concernem ao estabelecimento de um vasto campo de dados armazenado - cantigas, lendas, modinhas, fados, xaxados, xotes, aboios, cocos, emboladas, maxixes e o próprio samba. Esse amplo espectro cultural provou que a arte não é premissa exclusiva do gênio, todavia uma soma secular de diversos estilos amalgamados, anonimamente, que redundaram na arquitetura musical conforme se vê na atualidade.

No Brasil, particularmente, esboçou-se um cenário em que, além de a cultura do gênio na arte ter norteado os discursos promulgados por uma elite internacionalizada, havia (e ainda há) a questão dos conflitos raciais que permearam e potencializaram a luta de classes dentro da sociedade. Após a Abolição, principalmente, em 1888, quando viu-se o enorme contingente de negros alforriados formar uma massa abissal de desempregados, agravada pela importação de mão de obra europeia, é que a desigualdade racial se tornou mais que evidente, coloca Marc Hertzman (20 /3).

Paralelamente ao desejo nacionalista de erigir gênios como símbolos do poderio pátrio, forjou-se uma espécie de embranquecimento gradual populacional - de que já tratei em meus artigos anteriores (VACCARI, 2018, VACCARI, 2019, VACCARI, 2020a). 
gênio deveria, portanto, além de ser incompreendido, ter morrido na miséria e solitário, preferencialmente branco, ou, no mínimo, pardo, mestiço ou, como se dizia à época, “mulato". É quando chegamos, efetivamente, na figura do Padre José Maurício Nunes Carcia, compositor negro da Corte de D. João VI a partir de 1808, no Brasil então habitado pela realeza lusitana.

Como argumenta Antônio Campos, a respeito da idealização promulgada pelos historiadores e críticos de música sobre personalidades artísticas do século XIX:

A biografia de artistas sob o romantismo segue um roteiro pré-estabelecido e bastante disseminado: o biografado-herói, a quem é concedido o dom da genialidade, é posto em confronto com o rival-vilão, que movido pela inveja, emprega o seu tempo com ardis para embargar-lhe o reconhecimento artístico. Em consequência dessas ações, dificuldades materiais atingem o herói, que eventualmente morre em estado de miséria. Apesar de trágico, o desfecho da trama satisfaz o senso de justiça do leitor: o vilão amarga o sofrimento com o desdém do público e o gradual esquecimento do seu trabalho, e o gênio é eternizado pela própria obra. (CAMPOS, 2016, s/n)

Aqui, proponho, portanto, uma reflexão acerca da suposta genialidade de José Maurício, alardeada por teóricos da Musicologia desde Manuel Araújo Porto Alegre. Essa genialidade não teria sido, também, fruto de seu meio - no caso a cidade do Rio de Janeiro dos séculos XVIII e XIX - e não foi bastante propulsionada pela vinda da família real portuguesa ao Brasil, em 1808 ?

A genialidade, como em Beethoven e outros exemplos clássicos, não traduz, na verdade, uma cooperação coletiva secular de determinada sociedade, cuja cultura finda por aglutinar-se em uma prática musical que um compositor como José Maurício Nunes Carcia provavelmente souber aproveitar - mas por isso não está localizado solitariamente dentro dela?

A seguir começo a arguição a respeito das perguntas acima propostas e o desenvolvimento e síntese de suas possiveis respostas. 


\section{José Maurício e sua época: o meio social e racial carioca dos séculos XVIII e XIX}

C cenário é o Rio de Janeiro em fins do século XVIII e princípios do século XIX. A escravidão, longe de se extinguir, está em franca ascensão - segundo um documento de época, a então capital do Brasil importava de 20 a 30.000 africanos por ano, sendo todos vendidos na própria cidade e arredores dela (SCHLICHTHORST, 1943 [1 824-26], p. 129).

Ao contrário da boa relação entre português e negro escravizado que se tencionou forjar, desde o transporte da África para a América do Sul mostrava-se, senão um descuido, um quadro grave de degeneração humana:

Por mais cuidado que se tenha no tratamento dos negros durante a travessia do oceano, êles chegam ao Rio de Janeiro aparentemente em petição de miséria, todos magros e quasi sem excepção acometidos duma espécie de sarna, que thes cobre a pele com escamas branquicentas e torna sua côr preta e lustrosa, em cinzenta suja (SCHLICHTHORST, 1943 [1824-26], p.130).

Desse meio onde a escravidão tomava ainda a maioria dos homens, e onde o tráfico negreiro da África ainda tardaria a cessar sua mercantil atividade transoceânica - o tráfico seria, efetivamente, proibido, a partir de 1850 somente (SANTOS, 2018).

A estratificação social do Rio de Janeiro de então era em sua totalidade alicerçada nas relações escravagistas - quem era proprietário de escravos é quem regia os meandros e trâmites de toda a estrutura socioeconômica, e os demais ou eram negros alforriados, ou escravizados, ou homens livres. Esta última casta era extremamente incipiente e subdesenvolvida, e seria alçada ao lugar de pequena burguesia a partir de meados do século XIX, e, principalmente, a partir da Abolição da Escravidão, em 1888 (SOARES, 2007, p.85).

Conforme narra Sérgio Buarque de Holanda, o Rio de Janeiro ainda no século XVIII, segundo uma carta do conde de Cunha, primeiro 
vice-rei do Brasil, ao rei de Portugal, teria sido "[...] só habitado de oficiais mecânicos, pescadores, marinheiros, mulatos, pretos boçais e nus, e alguns homens de negócio, dos quais muito poucos podem ter esse nome, sem haver quem pudesse servir de vereador (HOLANDA, 2016 [1936], p. 108).

Recém-alforriado, ou já nascido livre, o negro situava-se então em um estrato social à parte. Rejeitado pelos comerciantes brancos que, mesmo a partir da proibição do tráfico, recusavam-se a admitir um empregado que teria tido qualquer relação com a escravidão - mesmo que fosse por longínqua ascendência, e alijado de sua própria raça por aqueles que se auto denominavam "pardos" ou "mulatos", ou seja, mais próximos do caucasiano, teve que, como eles, disfarçar sua negritude ou escondê-la. Segundo Ana Flávia Magalhães Pinto:

Num cenário em que aumentava o número de pretos e pardos livres e libertos, os significados atribuídos aos traços físicos dos indivíduos tinham tanta importância que uma saída emergencial seria tentar dissimular o óbvio, ou pelo menos agir como que suavizando a importância dos significados atribuídos à cor da pele e a outros traços fenotípicos. A tensão vivida nesse jogo de "me veja mas não me enxergue" me parece, justamente, a chave para entender as múltiplas tentativas de saida individual empreendidas pelas pessoas aqui observadas (MACALHÃES PINTO, 2018, p. 148$)$.

Referindo-se a Joaquim Maria Machado de Assis (1839-1908), provavelmente o maior escritor em prosa do Brasil, Luís Cama (18301882), escritor e patrono da Abolição da Escravatura Brasileira, e José do Patrocínio (1853-1905), também abolicionista, jornalista e escritor, a autora almeja traçar o perfil dessas personalidades como que destoantes da ignomínia a que eram lançados, praticamente, todos os negros libertos no seio de uma sociedade que contava apenas com duas castas sociais: proprietários de escravizados e escravizados.

A essa mesma ordem de personalidade teria pertencido o Padre José Maurício Nunes Carcia (1767-1830). Mesmo que os musicólogos tenham descrito sua trajetória de gênio de maneira exagerada, há de se convir que representou, sem dúvida, um marco na Música Brasileira 
sem precedentes até então. Luiz Heitor, por exemplo, em Música e músicos do Brasil ( 1950) tece comentários sobre o compositor que ostentam, quiçá, laivos de embranquecimento estrutural como o seguinte: "José Maurício ainda continua na sombra" (HEITOR, 1950, p.101).

A associação do Padre com a sombra e a obscuridade são recorrentes na Musicologia Brasileira, conforme demonstrei em Vaccari (2020). Ao dotá-lo de características físicas ou psicológicas que remetem ao escuro ou ao negro - sempre com um tom pejorativo negativo - parecem querer ocultar a negritude de José Maurício. $O$ mesmo acontece na seguinte passagem, em que Heitor argumenta serem necessários esforços de "[...] clara e admirável energia essa instrução dada a um menino pobre e de côr, precisamos lançar os olhos sôbre o meio em que vivem nossos personagens" (HEITOR, 1950, p. I10).

A clareza atrelada à instrução e à energia, contrapõe-se ao menino "pobre e de cor". No entanto Heitor, em certos fragmentos, parece retratar fielmente a Corte Portuguesa instalada no Brasil a partir de 1808, seu desgosto por tudo que é brasileiro (HEITOR, 1950, p.1 18).

Nesse ambiente hostil ao que seria nacional, com o acréscimo de ser ele mesmo um negro, ou seja, ter raizes ancestrais em outro continente, José Maurício talvez tenha abarcado as contradições mais inerentes ao que significa ser brasileiro: receber o opróbrio do desprezo estrangeiro, sentindo-se como que "desterrado em sua própria terra" (HOLANDA, 2016 [1936], p.35).

Antes de ter, portanto, seu lugar assegurado como um dos grandes compositores brasileiros, o Padre José Maurício representaria, de acordo com este raciocínio, o perfeito símbolo do seu estrato social: procurando validar-se e afirmar-se através de sua individualidade, por ter sido hostilizado pelo seu meio, teria reunido em si qualidades de seus ascendentes diretos e indiretos. Possui, desse modo, um significado social genuinamente grande, que transborda a aura da mitologia de gênio que morreu na miséria - não seria ele, na verdade, fruto de uma sociedade extremamente dividida, a quem exerceu profunda resistência, e representante autêntico de uma minoria na Corte lisboeta infiltrada no Rio de Janeiro? 


\section{O Padre José Maurício e sua simbologia: a brasilida- de da Modinha}

A sua tão promulgada genialidade teria consistido, porém, em um incrivel talento para consubstanciar estilos $e$, em todos eles, na missa e na música para cravo, imprimir um caráter brasileiro inconfundivel - por meio do gênero da Modinha. Na obra Música do Brasil, de 1967, Eurico Nogueira França já daria a pista do que significaria o estilo modinheiro do Padre:

[... com todos os seus resquícios, não raro, de linha melódica de ópera italiana, a dar um certo sobressalto profano às árias sacras, a música de José Maurício tende, às vêzes, a se naturalizar por um caminho inesperado: o da modinha: certas inflexões, certo dengo, certa ternura nossa a impregnam, a modificam, a transfiguram, e antecipam a transformação modinheira que a expressividade melódica italiana veio sofrer no Brasil (FRANÇA, 1967, p.56).

A derivação antropológica e cultural que redundou na modinha, estilo híbrido lusitano e dos trópicos - conforme já argumentei em meu artigo (VACCARI, 2019), deixa entrever que o gênero possui um singular poder de síntese musical, traduzida na sua própria história.

Tendo o dom de aglutinar estilos, escolas e castas sociais distintas, reinaria com exclusividade na época do Brasil Colônia. A modinha era a favorita tanto do menestrel urbano, do negro que fazia serenata acompanhado ao violão ou viola de arame - instrumento do Padre José Maurício Nunes Garcia - como dos salões dos senhores de escravizados, onde a senhora branca dedilhava ao piano as modinhas então em voga. Prática herdada de Portugal, onde constantemente vemos descrito, num romance ou follhetim do século XIX, o momento em que a jovem sinhá se põe a cantar uma canção de caráter modinheiro, como a passagem a seguir, de $O$ primo Basilio, do escritor português Eça de Queiroz (1845-1900).

Luisa, lisboeta da ascendente burguesia, passa o dia a ler folhetins, romances e novelas de cunho romântico. Quando seu marido Jorge necessita viajar a trabalho, exaspera-se na solidão da alcova de muther rica e bem tratada, e o acaso traz à capital seu primo Basilio, que 
morava há anos em Paris e a seduz com seus trejeitos e ares de janota. A trama termina em tragédia já que suas cartas com o primo amante são descobertas e sequestradas pela empregada, Juliana, o primo nega a the dar auxilio e foge para a França, e na volta do marido Luísa morre numa febre psicossomática.

No trecho a seguir, ainda no princípio do romance, Basilio canta uma modinha para Luísa e outros personagens:

Basilio riu. Uma vez que tinha sucesso, então ia dizer-lhes uma modinha brasileira da Bahia. Sentou-se ao piano, e depois de ter preludiado uma melodia muito balançada de um embalado tropical, cantou: Sou negrinha, mas meu peito/ sente mais que um peito branco. [...] Era a história de uma "negrinha" nascida na roça, e que contava, com lirismos de almanaque, a sua paixão por um feitor branco (QUEIROZ, 1912 [1878], p.126).

Neste excerto vemos pronunciadas as características principais da modinha da época: hibridez, não apenas no quesito de estilo - uma modinha proveniente da Bahia, no Brasil, cantada em um lar de Lisboa - mas também racial. Apesar de, ao menos aparentemente, insinuar uma suposta democracia racial, que só existira nos contos de ficção, a passagem traduz uma história bastante comum no século do Romantismo: modinhas trazidas de classes sociais mais baixas executadas nos salões e salas de jantar burgueses.

A questão racial mencionada acima é a mesma que permeia a trajetória do Padre José Maurício Nunes Garcia - Cleofe Person de Mattos afirma que a ascendência do músico era formada por eventuais relações entre brancos e negras escravas ou alforriadas. Seus pais, Vitória Maria da Cruz, e Apolinário Nunes Garcia, são descritos, na sua certidão de casamento de 1762, ambos como pardos forros (MATTOS, 1997, p. 17-8).

Os avós do Padre estão denominados, no mesmo documento, na parte paterna "Anna Correa do Desterro Crioula da Guiné e de Pai incognito", e na materna "Joana Clz, crioulla e de pay incognito" (fonte primária apud MATTOS, 1997, p.17-8). 
Dessa forma ambos os avôs incógnitos podem ter sido, ocasionalmente, brancos. A discussão colocada aqui e em outros artigos meus (VACCARI, 2020a, VACCARI, 2020b), é que tendo em sua linha genealógica elementos brancos ou não, ele deve ser considerado negro. A suposta parcela branca não deve alienar seus traços e sua ancestralidade africana, mesmo porque o estereótipo do "mulato" - "cor de mula" já há muito não tem sido utilizado cientificamente, e o termo "pardo" por vezes pode soar de forma eufemística. Em a História do negro no Brasil, argumenta-se que os termos "[...] moreno, escuro, cafuzo ou qualquer outro efemismo [é] usado para dissimular a cor" (BRASIL, 2004, p.386).

A própria origem da Modinha, entretanto, embora ainda desperte controvérsias, é, fundamentalmente, negra. Em A modinha e o lundu: dois clássicos nos trópicos, Edilson de Lima pontua que:

\begin{abstract}
A modinha e o lundu são dois gêneros musicais que têm acompanhado a história da música luso-brasileira, já há mais de dois séculos. Gêneros abordados por músicos de renome, tais como Marcos Portugal (1762-1830), Antonio Leal Moreira (1758-1819), José Maurício Nunes Garcia (1767-1830) [...] tornaram-se veículos da expressividade da época, difundindo-se rapidamente em todas as classes sociais, sem distinção, antes mesmo do alvorecer do século XIX (LIMA, 2010, p.10).
\end{abstract}

De fato, se remontarmos ao despontar da modinha, geralmente chegaremos ao nome do músico negro brasileiro Domingos Caldas Barbosa (1740-1800) - senão responsável pelo efetivo nascimento do gênero, de cunho popular-tradicional, pelo menos o grande difusor da modinha em Portugal. $\bigcirc$ seu maior biógrafo, José Ramos Tinhorão, no entanto, não exime-se de alcunhá-lo eufemisticamente como "pardo" (TINHORÃO, 2004, p. 11 ).

A imagem que acompanha o livro, que o musicólogo supõe ser a única disponivel de Caldas Barbosa, mostra antes mais um retrato embranquecido, onde não vemos nem ao menos um traço sequer de negritude. 


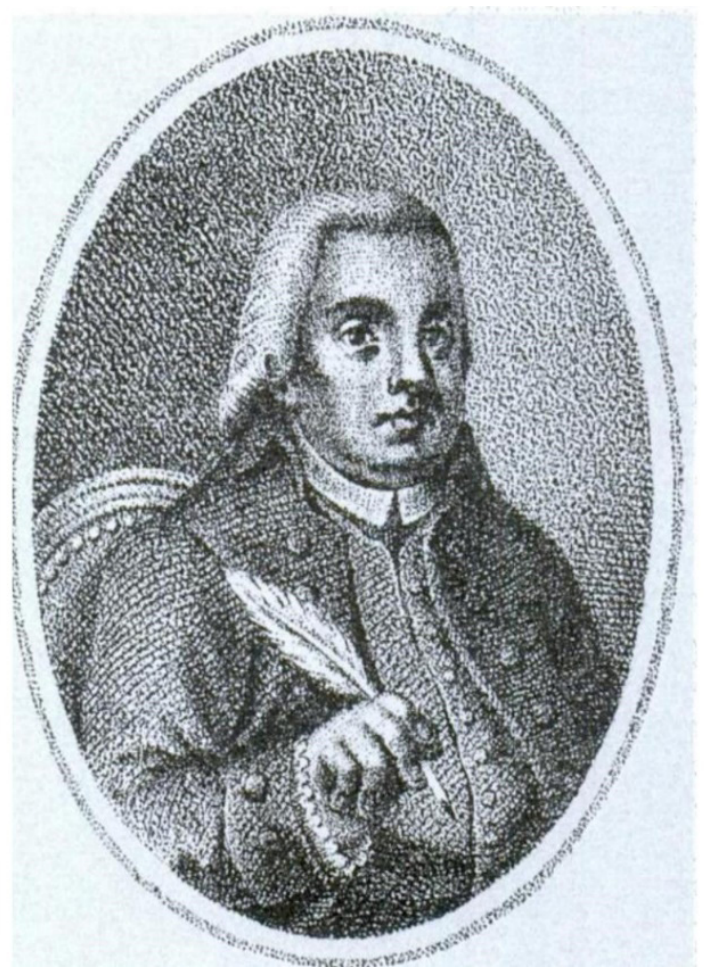

Fig. I. Domingos Caldas Barbosa: embranquecido? Fonte: Tinhorão (2004, p. 10)

primeiro volume do Jornal de Modinhas com acompanhamento de cravo, publicado, inicialmente, em 1792 em Lisboa - o último seria em 1796, cuja inscrição na capa versa que: "No primeiro dia e Quinze de cada Mez, sahirá huma Modinha nova" (ALBUQUERQUE, 1996, p. 1 ), traz no cerne a síntese do que seria a modinha à época. Nele vemos 24 modinhas, portuguesas e brasileiras, onde há que se estabelecer um critério padrão de composição: quanto ao texto todas empregam poemas de amor/desilusão ou abandono do (a) bem amado (a).

Quanto à música, vemos a abundância do uso de figuras quiálteras, principalmente tercinas, no acompanhamento do cravo da mão direita, enquanto a esquerda executa um baixo quase sempre em cadência I - V- I ou I - IV - V - I. 


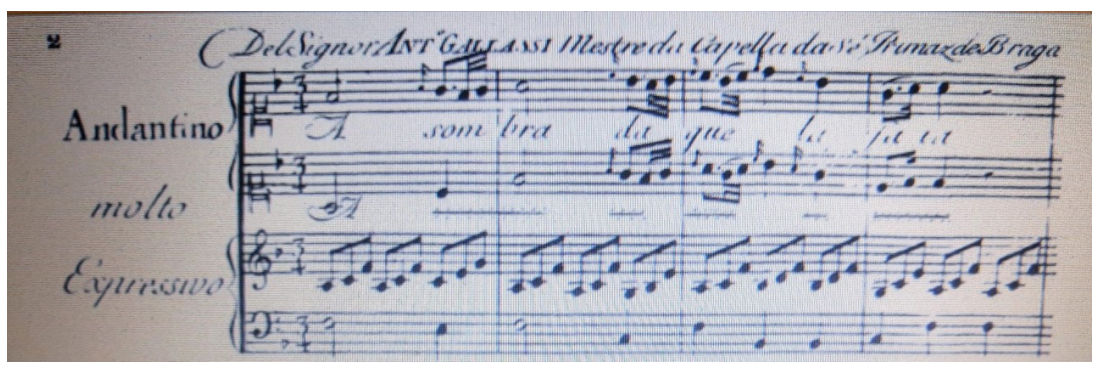

Fig. 2. Modinha "À sombra daquela faia", de Antônio Galassi (1750-1795), Mestre de Capela da Sé de Braga, Portugal. Fonte: Albuquerque (1996, p.34)

Há uma certa tendência à preferência pela tonalidade de Sol Maior e Fá Maior. $\bigcirc$ estilo desta modinha portuguesa é similar ao de muitas outras, mesmo brasileiras: além do acompanhamento, a ornamentação excessiva das vozes em dueto - repare as apojiaturas e os melismas.

Francisco Domingos Milcent (1765-1797), foi o editor do Jornal de Modinhas, que, aparentemente, findou devido a sua morte. Uma edição póstuma de 1820 reunia todos os volumes com todas as modinhas publicadas. Dali pode-se auferir que:

- As tonalidades favoritas são: Sol Maior ( 3 modinhas), Fá Maior (6 modinhas), Mi bemol Maior e Si bemol Maior (12, sendo 6 de cada), Lá menor (3), Dó Maior (3),Lá Maior (2), entre outras que não contaram mais que uma das 7 modinhas restantes cada;

- Quanto às fórmulas de compasso temos o seguinte: 2/4 (17), 6/8 (10),3/4 (9), 2/2 (6), 3/8 (4).

Oestilo dessas modinhas é caracteristicamente bem virtuoso no que compete às vozes solistas, e o acompanhamento ao cravo sempre homofônico, pouco imitativo, utilizando a figuração tercinada comum ao Baixo de Alberti, nome que deriva do italiano Domenico Alberti (1710-1740), e que consiste em tocar as notas do acorde uma a uma, frequentemente com a repetição de algumas delas. 


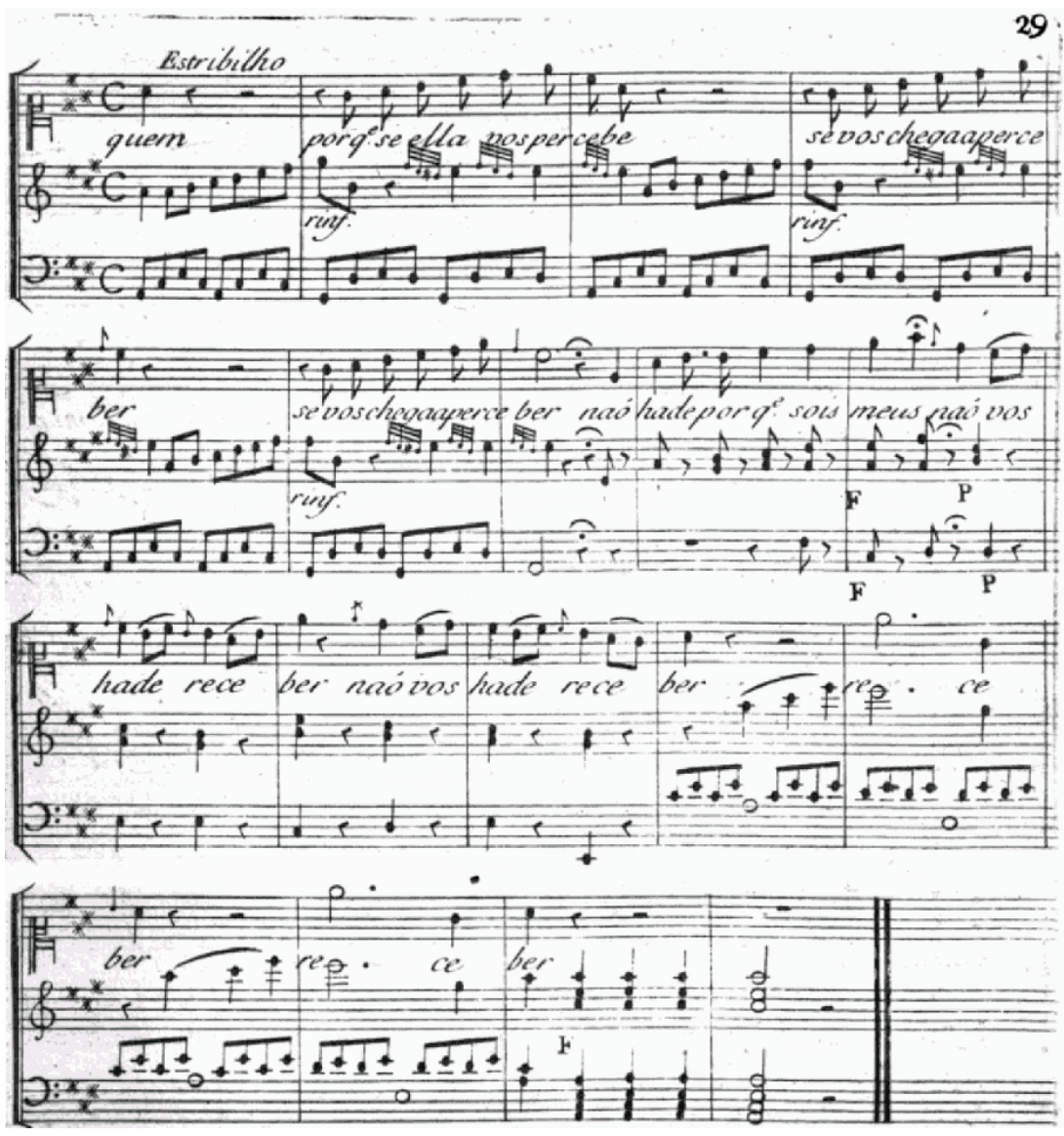

Fig. 3. Modinha "Cuidados tristes" de Marcos Antônio - pseudônimo de Marcos Portugal (1762-1830) - uso do "Baixo de Alberti". Fonte: Milcent (1820, p.29)

Contemporâneo de José Maurício, Marcos Portugal veio ao Brasil em 1811, sendo empossado Mestre da Capela Real assim que chegou. Segundo André Cardoso, "sua nomeação causou considerável decréscimo na atuação de padre José Maurício como mestre-de-capela" (CARDOSO, 2008, p.98). 
Para Cardoso, o rei provavelmente preferia as peças do português, porque representariam melhor o jeito de se compor na Europa à época. No entanto, ao analisarmos esta modinha acima, vemos exatamente um protótipo modinheiro de seu tempo: exceto a tonalidade, das mais incomuns no gênero - a primeira parte em Lá Menor, a segunda modulando para Lá Maior - a figuração rítmica do acompanhamento está quase todo composto por "Baixo de Alberti", alternado com uma escrita acordal homofônica. A escrita vocal, recheada de notas longas sustentadas e apojiaturas, nos lembra o intrincado virtuosismo dos castrati italianos.

Mário de Andrade, em seu volume Modinhas imperiais (1930), no entanto procura desmistificar a procedência burguesa do gênero, atribuindo-lhe feições populares e "vagos apêlos raciais" (ANDRADE, 1980 [1930], p.5), e pontua o caráter tradicional da modinha, segundo ele com "versos a maioria das vezes anónimos, e, si de autores com nome impresso, tão polpudos de mediocridade que mais os valorisaria o mistério do anonimato" (ANDRADE, 1980 [1930], p.6).

Parece desejar atestar, dessa forma, o poder sintético da modinha em traduzir elementos populares, de modo a unificá-los em um conteúdo artístico próprio. Dado seu grande anonimato, teria uma força de tradição oral que poucos gêneros nacionais tiveram no Brasil Colônia - lembrando que a Modinha e o Lundu são considerados os gêneros precursores da música nacional, afirma Paulo Castagna em Stroeter e Mori (2020).

Ao colorir a música sacra com acentos de modinha (ANDRADE, 1980 [ 1930$]$ ), José Maurício teria condensado a música brasileira e a europeia, misturando matizes que redundariam em obras com simbolismo nacional inconfundivel, coloca o autor.

que definiria essa simbologia seria, por exemplo, vários elementos utilizados pelo compositor em suas modinhas. Das que ficaram à posteridade, a saber, "Beijo a mão que me condena", "Marilia si me não amas, não me diga a verdade", "No momento da partida", e "Estas lágrimas sentidas", temos as seguintes tonalidades, respectivamente: Fá Maior, Ré Menor, Si bemol Maior e Lá Menor. Ou seja, são tonalidades entre as mais utilizadas da compilação do Jornal de Modinhas - vide página 12 - mesmo Lá Menor, que aparece somente em três delas, no entanto aparece uma vez nas Modinhas Imperiais de Mário de Andrade, 
e Ré Menor, que é a tonalidade de apenas uma delas, neste último é a tonalidade de três delas (ANDRADE, 1980 [1930]).

A título de comparação, peguemos um exemplo de modinha popular-tradicional abordado por Ermelinda Paz:

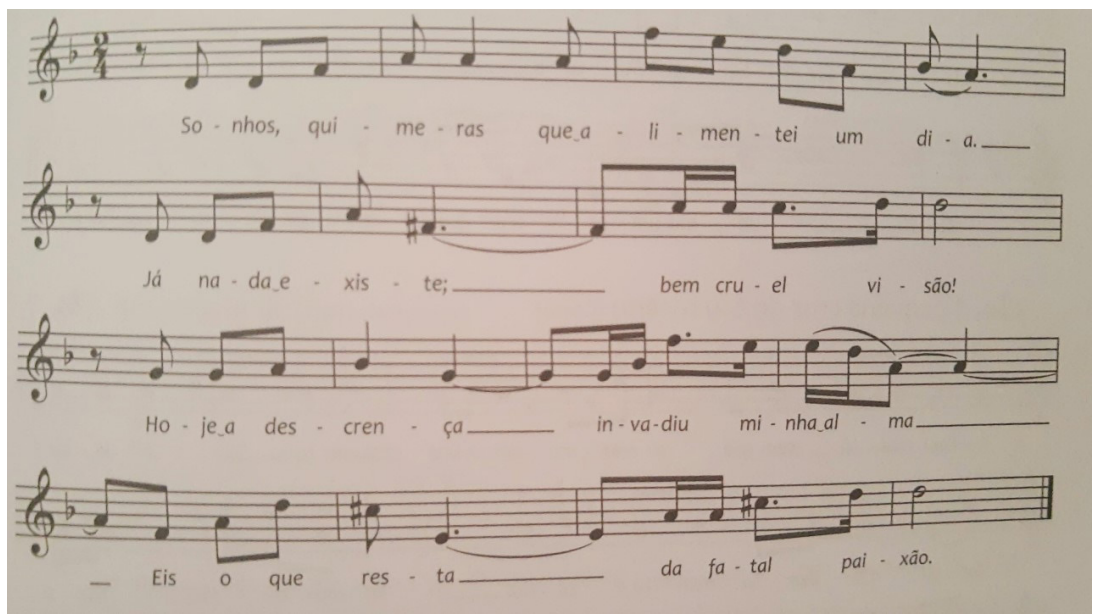

Fig. 4. Modinha "Sonhos, quimeras". Material folclórico. Fonte: Paz (2010, p. 109)

Aqui a tonalidade de Ré Menor, a mesma empregada por José Maurício em "Marilia si me não amas...", aparece com uma pequena passagem por Ré Maior - compasso 6 - e a nota sensível, no caso Dó \#, surge como afirmadora da tonalidade.

Repare que a mesma tonalidade e desenho melódico similar são encontrados na modinha "Escuta, formosa Marcia...", recolhida por Mário de Andrade: 


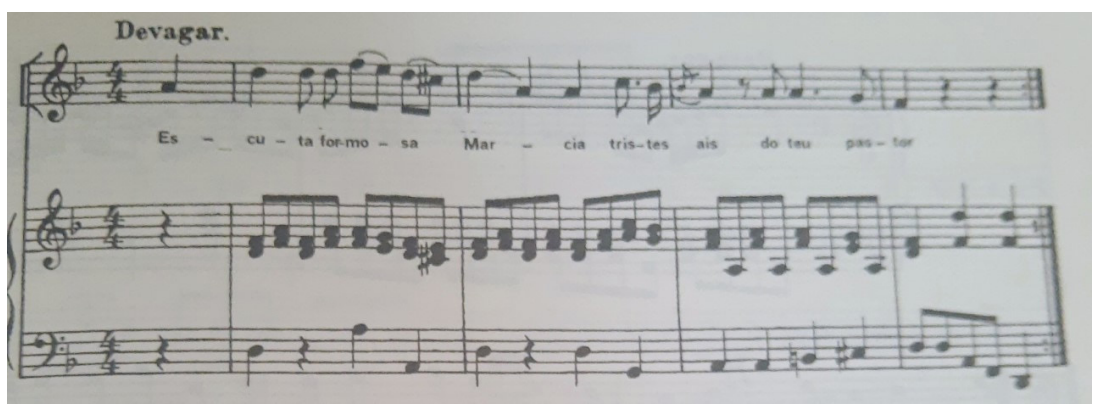

Fig. 5. Modinha "Escuta, formosa Marcia...". Fonte: Andrade (1980 [1930], p.21)

A melodia de ambas as modinhas tem a nota Fá natural como ponto culminante, além de utilizarem a mesma tessitura vocal - Ré3 a Fá4. Isto denota que esse arquétipo melódico parecia ser uma constante na construção estrutural modinheira do século XIX. A mesma semelhança pode ser vista na modinha "Marília, si me não amas...", de José Maurício:
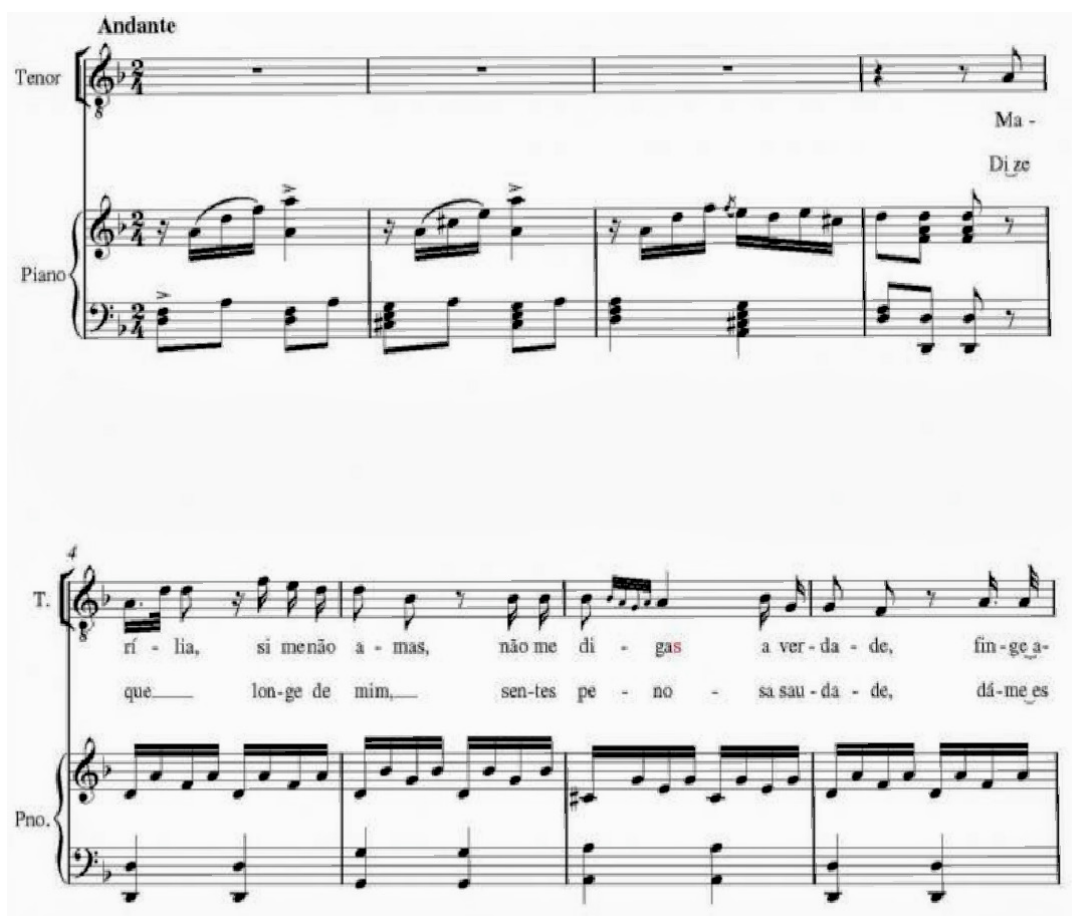

Fig. 6. Modinha "Marilia si me não me amas, não me diga a verdade", de José Maurício Nunes Garcia. Fonte: Campos (2017, p.1) 
protótipo melódico é similar ao das duas anteriores: a polarização da nota Fá Natural como ponto estratégico, que constitui o elo entre as três modinhas, torna o desenho parecido. Ao cantarolar os três exemplos se tem uma visão mais ampla de como essa sonoridade é parecida.

acompanhamento, como as modinhas presentes no Jornal de Lisboa, reflete a tendência em escrever em cadências IV - V - I - Compassos 6, 7 e 8. A mão direita, por sua vez, após um curto tema imitativo de introdução, obedece o padrão consagrado de composição sobre o Baixo de Alberti - nos mesmos compassos.

A similitude melódica destas modinhas, nos assume auferir que, provavelmente, havia muitas outras escritas da mesma forma. No próprio Jornal de modinhas, o único espécime escrito na tonalidade de Ré Menor, também possui a mesma tessitura vocal, com enfoque no Fá Natural agudo da voz superior:

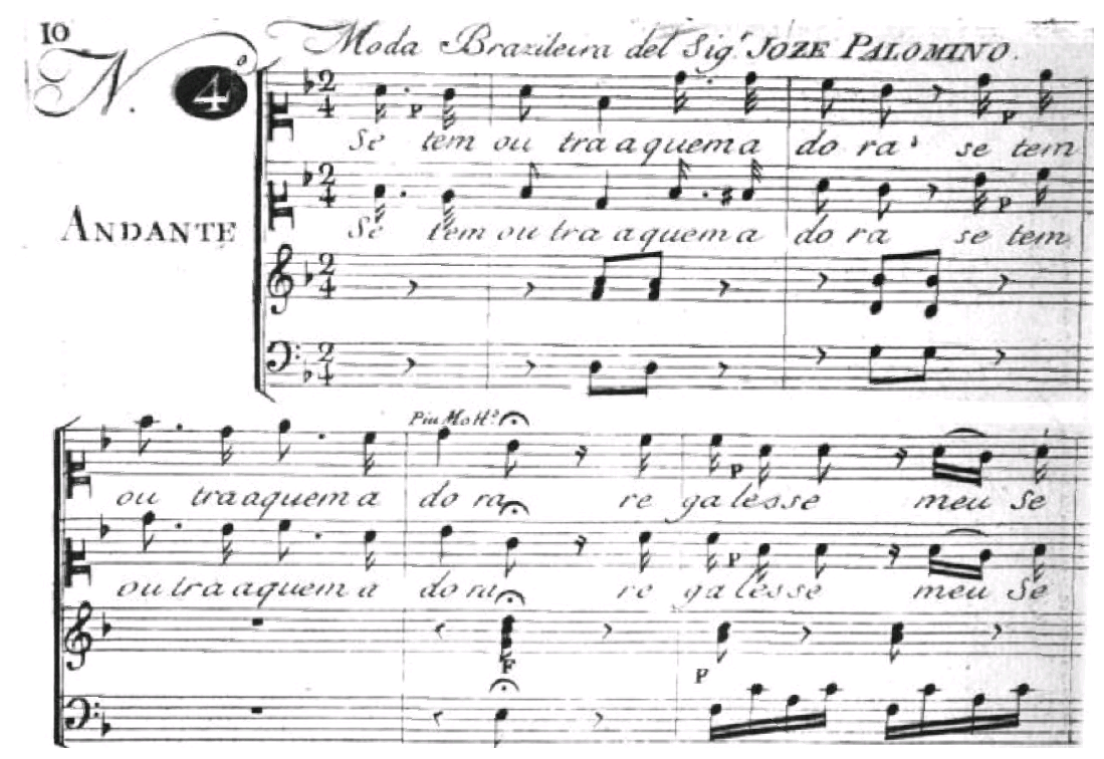

Fig. 7. Moda "Se tem outra a quem adora", de José Palomino (1755-1810), compositor espanhol que residiu algum tempo em Lisboa. Fonte: Milcent ( 1820, p. 10). 
A frase que começa com "se tem outra", na voz de soprano foi escrita nas notas Ré, Mi e Fá, que caracteriza, além da modinha mauriciana, várias outras da mesma época, como pudemos perceber. A Seção B principia e utiliza como estrutura básica também o Baixo de Alberti - a partir do compasso 5.

Observe como os exemplos acima expostos trabalham com o mesmo motivo - ainda que com ritmos distintos, em torno de Ré, Mi e Fá Natural - o que pode enfatizar que era uma prática comum da modinha popular que ressoou nos salões burgueses da mesma forma.

Delineia-se o arcabouço da história do padre negro compositor apoiando-se na teoria de "Eurocentrismo", ou Hegemonia da Europa no mundo do Século XIX, particularmente nas Américas e no Brasil. Utilizouse, para esse fim, a obra do historiador Sergio Buarque de Holanda que, em Raízes do Brasil (HOLANDA, 20 16), de 1936, define a terra brasileira como uma terra de desterrados - no sentido de que é um país com clima tropical e multiétnico que adotou formas de cultura, de civilização importados de uma nação completamente dispar, com hábitos estranhos aos nossos e desprovidos de significação para o nosso povo e nossa cultura. Essa complexa e destoante hibridação nos trópicos redundou na sensação de que os brasileiros, ainda hoje, sentem-se, no próprio solo nacional, como que estrangeiros. 


\section{Conclusões e considerações finais}

Através dos exemplos acima e da comparação pudemos ver que a Modinha possui pequenos motivos que se repetem ao longo de sua história. Esses motivos se constituem fatores unificadores de sua linguagem musical e retórica, como forma de atingir determinados objetivos dramáticos da partitura, no caso a expressão do afã e da intemperança do amante romântico.

Com isso espero ter ajudado a compreender que a noção de gênio está, também, atrelada à contextualização sócio-histórica de sua procedência e ambientação cultural - ela não é, conforme viu-se acima, uma prática isolada de seu contexto original. $\bigcirc$ fetiche do gênio incompreendido que morre na miséria, que começa na História da Música Ocidental com a releitura da biografia de Mozart (1756-1791), adquiriu contornos semelhantes no Brasil com o "Mozart dos trópicos", José Maurício Nunes Garcia (1767-1830).

A discussão acerca de sua procedencia humilde, levantada desde Manuel Araújo de Porto Alegre no século XIX, até Cleofe Person de Mattos, nos dá a medida em que uma aura de quase divindade foi atribuída ao compositor, potencializada por essa origem, e pelos entraves raciais que a vida e a Corte Portuguesa o fizeram passar. Sua história, entretanto, vista por esse prisma etnomusicológico pode nos alicerçar a construir um imaginário livre de preconceitos, onde a Antropologia e a História nos façam entrever o todo, o ser humano e suas realizações em conjunto, pelas superações coletivas e um destino em comum.

É mister colocar que, mesmo aparentemente apartado de sua ex-colônia, a partir da independência de Portugal, em 1822, o Brasil continuou sofrendo a esmagadora influência hegemônica europeia, menos ibérica que francesa e inglesa, em termos econômicos e culturais. Na música, no entanto, a predominância alternava-se ora pelos germânicos, ora pelos italianos, e a confluência dos dois foi o que, culturalmente, estruturou toda a obra de José Maurício Nunes Carcia (MATTOS, 1997).

Contraditando, portanto, o mito de "democracia racial" propagado pelo sociólogo Cilberto Freyre (FREYRE, 2016), propõe-se uma visão em que o Brasil multirracial é, na verdade, um país sectário em que, embora predominante, a raça negra ainda sofre as agruras da desigualdade e da miséria humana. A hegemonia europeia no Brasil do 
Século XIX deu-se devido a diversos fatores, entre eles o cientificismo que afirmava ser o branco superior no quesito intelectual - conceito que determinou e perpetuou o racismo como algo plenamente natural e até desejável - e o nacionalismo que procurou assentar essas teorias na prática (HAZAN, 2009). Além da hegemonia europeia em relação ao Brasil, havia, ainda, a grande divisão interna do país que se dava em duas grandes castas: a dos senhores e a dos escravos. Entre elas circulavam alguns tipos que, com raras exceções, conseguiam mobilidade social ascendente - mas, quase impossivel um escravo liberto um dia chegar a vestir roupas de algodão.

A pertença à classe proprietária pressupunha, além do elemento racial, o partilhar de um conjunto de valores, estilos e comportamentos moldados à concepção europeia de progresso e civilização. É dentro desse quadro que, durante a maior parte do século XIX, as óperas francesas e italianas, mas sobretudo essas últimas, foram consumidas obsessivamente pelas elites que, assim, se diferenciavam culturalmente das ralés livre e escrava que formavam a maioria da população (HAZAN, 2009, p.25).

Portanto, mais do que hegemonia europeia, e aliada a ela, sofria a nação brasileira de uma preponderante elite financeira que se identificava antes com a elite e cultura europeias. Ditando as regras do que deveria ser a Arte e a Cultura em geral, essa elite dominou, durante longos séculos, o pensamento nacional no que tange aos (bons) costumes, à literatura, à música, ao teatro, à dança, à política e à imprensa. No seio dessa sociedade, ainda escravagista, anacrônica e colonial, nasceu José Maurício, na capital do Império, negro e neto de escravizadas. Ambos, portanto, dependiam da esfera da lgreja Católica para se consolidarem, o que a coloca como praticamente o único meio de um negro liberto ascender socialmente no Império. Sob o prisma da simbologia histórica, é provável que homens como José Maurício tenham representado não apenas uma promoção social pessoal, porém também de toda a sua familia - que teria investido, de certa forma, e contribuído para a sua ordenação como padre (OLIVEIRA, 2008). Esse processo, destarte, constituiria uma alegoria representativa - no campo do macrocosmo - de diversas famílias que teriam se empenhado em promover tal mobilidade social, formando, na sociedade como um todo, uma pressão que pode ter redundado na Abolição. 
O chamado "defeito de cor", desse modo, não foi um impedimento à sua ordenação, sendo ele, inclusive, tratado até de forma meritocrática por alguns autores antigos como Visconde de Taunay. Para alguns biógrafos, inclusive Person de Mattos ( 1997), o fato de José Maurício ser negro exerce um certo fascínio - sendo objeto quase fetichista de veneração musicológica por sua procedência pobre e sua cor. $\bigcirc$ mito feito e refeito, através dos séculos, de um compositor negro humilde que "não pedia nada" e era completamente subordinado aos seus superiores, remonta à ideia binária histórica de que o negro deveria ser ou extremamente obediente ou insubordinado (HOLANDA, 2016). $\bigcirc$ historiador Sérgio Buarque de Holanda, no entanto, parece, de certa forma tecer um preconceito ao estigmatizar o negro como indolente e causador principal da famigerada "preguiça dos trópicos". Ele chega ao ponto de afirmar que "a própria criação do mundo teria sido entendida por eles como uma espécie de abandono, um languescimento de Deus". (HOLANDA, 2016, p.72). Como avaliar, entrementes, qual povo mais propício ao ócio, já que é o lusitano colonizador também conhecidamente desfrutador da modorra?

O efeito desejado por uma anulação do "defeito" parece ter sido a perpetuação do rígido catolicismo ibérico, instaurado em solo brasileiro, ainda não sem uma violenta resistência que quase the logrou os objetivos. Mas é claro, como poderia o europeísmo transplantado adaptar-se à monocultura escravagista em que se davam senão relações contrárias, completamente estranhas às empreendidas em Europa? (RIBEIRO, 2015 [1995])

Person de Mattos (1997), a mais importante biógrafa do padre, não consegue especificar, mesmo após profunda pesquisa em fontes primárias e documentação, a ascendência branca de José Maurício. Isso nos coloca novamente a pergunta já observada em meu artigo (AUTOR, 2018): não seria ele um negro que, por diversas razões históricas, e devido ao próprio "defeito", fora embranquecido pelos autores romanescos de folhetim, do Século XIX e XX?

É mister notar que, qualquer leigo que ouvir a música de José Maurício, há de considerá-la plenamente europeia, particularmente germânica e italiana - esta em menos proporção, aquela em mais. Assim se dá, paulatinamente, a estruturação de sua obra: em sua primeira fase, que compreende o período do final do Século XVIII até a data de 1808, ela é basicamente setecentista, ou seja, influenciada pelos estilos 
francês e italiano dos anos 1700. A partir de 1808, data da chegada do Rei Dom João VI ao Brasil, que se instalará com sua corte na capital Rio de Janeiro, o padre viu-se compelido a assumir outro estilo composicional. Da simplicidade harmônica e singela estruturação de sua fase anterior brotaram novos matizes, oriundos, em grande parte, da ópera italiana, porém ao novo jeito de fazer musical se amalgamaram antigas práticas europeias, como a polifonia e a fuga. Dessa forma, juntamente ao recitativo e as árias de grande virtuosidade vocal, permaneceram em sua obra a ornamentação exagerada do Barroco, constituindo José Maurício um compositor que pode abarcar, em uma mesma peça, elementos barrocos, do Rococó, do Classicismo e da ópera do Pré -Romantismo e do Romantismo Rossiniano. Ele é, por consequência, um dos compositores brasileiros, junto a Carlos Comes, que mais sentiu a hegemonia musical europeia em suas peças. Não há sequer uma característica em seu estilo que possa qualificá-lo de legitimamente brasileiro, a despeito do que muitos musicólogos já afirmaram sobre ele - suas peças são, sim, extremamente europeizadas, e ainda que possuam certas idiossincrasias, podem ser consideradas verdadeiras imitações literais dos compositores italianos e germânicos - vide o seu Réquiem de 1816 , quase todo inspirado no Réquiem de Mozart de 1791 que chega a ser praticamente um plágio.

No entanto, seu valor histórico é inegável - pela primeira vez desde a colonização deu-se a ascensão de um compositor brasileiro, cuja maestria podia ser equiparada a de um europeu como o português Marcos Portugal. A hegemonia do germanismo foi estruturada pela sua admiração pelos gênios austríacos Haydn e Mozart, e não haveria de ser diferente - um compositor negro, neto de escravos, nascido em solo brasileiro, jamais poderia ter sido um Heitor Villa-Lobos (1887-1959), compositor brasileiro nacionalista, da mesma forma que o mulato Carlos Comes (1836-1896) tem uma obra quase toda sob a influência hegemônica do Italianismo operístico do Século XIX.

Na historiografia musical brasileira, poucos são os que conferem ao compositor José Maurício o lugar que the seria devido - ou o idolatram ou o menosprezam. Seus primeiros biógrafos, Manuel de Araújo Porto Alegre (1806-1879), o Visconde de Taunay (1843-1899) e Luiz Heitor (1905-1992), trazem arraigada uma noção deveras romântica do padre, compositor a seu ver mulato que, devido a sua cor e origem humildes haveria sofrido cruéis privações sociais e as teria aceitado beneplacitamente. 
Mesmo a biógrafa mais completa de José Maurício, no entanto, Cleofe Person de Mattos (1913-2002), embora seja a maior fonte sobre o padre que conhecemos, carece de renovações críticas contemporâneas. Falta-lhe a imparcialidade de poder julgar a obra do compositor sob a ótica de um cientista, e não apenas de um admirador contumaz.

Nenhum dos autores acima tratou da premissa de que José Maurício foi um compositor que atuou sob a égide hegemônica avassaladora do europeísmo de seu tempo - principalmente germanismo e italianismo - que foi determinante para a estruturação de toda a sua obra. Talvez somente Mário de Andrade (1893-1945) tenha compreendido o padre em sua totalidade - nem coitado nem gênio e, embora tenha sido o maior compositor colonial brasileiro, não ultrapassou os italianos de seu tempo, o que, "universalmente, era pouco" (ANDRADE, 2006, p. 131).

clareamento de José Maurício, perpetrado e induzido por historiadores e musicólogos provenientes da incipiente academia brasileira, nos séculos XIX e XX, não deixou, no entanto, de vicejar, fortemente, até a contemporaneidade. Em um texto relativamente recente para uma história de mais de 250 anos, Ricardo Bernardes afirma, contundentemente, ter sido o pai do Padre "[...] (segundo registros) de raça branca [...]" (BERNARDES, 2001, p.42). Porém a questão que se pondera é que registros são esses, que o autor não cita, ou seria mera conjetura para cristalizar a etnia mestiça de José Maurício? Na mesma publicação há a assertiva de que "o tempo de José Maurício à frente da Real Capela é claramente um período de transição estilística entre suas duas práticas" (BERNARDES, 200 l, p.42). Chama a atenção tal assertiva, em vista de que ela aparece em destaque na página do artigo, abaixo de uma foto em que o Padre aparece visivelmente clareado. As tais fontes a que Bernardes se refere seriam quais exatamente, já que a própria Cleofe Person de Mattos, em sua biografia, pontua que Apolinário Nunes Garcia, pai do Padre, teria sido, segundo a sua certidão do casamento, um "pardo forro"? (MATTOS, 1997, p. 17).

Essa aparente tentativa de clareamento, seja ela consciente ou não, denota uma certa dificuldade da musicologia brasileira com as figuras negras - vide o caso de Carlos Comes, quase sempre lembrado como compositor mulato, mas que também teria sido embranquecido pelas fotos da historiografia. Essas personagens que antecederam o Modernismo em música se ressentiram, quase sem exceção, dessa tendência histórica de clareamento que, parece estar inserida num contexto maior 
- o contexto de europeísmo ou hegemonia caucasiana do explorador que remonta aos séculos de invasão colonizadora. Longe de ser menos potencializada por meio dos anos, é ela quem domina, ainda, parte da historiografia brasileira - uma historiografia positivista, anacrônica, que apenas estuda figuras musicais nacionais do século XIX, e com um crivo essencialmente descritivo, não se aprofundando em questões antropológicas ou sociais.

Há uma corrente, no entanto, que desde o princípio do século $X X I$ se antepõe à visão romantizada dos ícones brasileiros da música do século XIX. Espero ter contribuído para que a visão antropológica do Padre prevaleça ante o preconceito e as visões pseudocientíficas ainda presentes em nossos dias.

\section{Referências}

ALBUQUeRQUE, M. J. D. Jornal de Modinhas: Ano I. Lisboa, Instituto da Bilbioteca Nacional e do Livro, 1996 [1792].

ANDRADE, M. de. Ensaio sobre a música brasileira. Belo Horizonte, Itatiaia, 2006 [ 1928].

[1930].

Modinhas Imperiais. Belo Horizonte, Itatiaia, 1980

BERNARDES, R. Corte de D. João VI: obras profanas. São Paulo, Funarte, 2001.

BLACKING, J. How musical is man? Washington, Washington Press, 1973.

CAMPOS, A. Marcos Portugal x Padre José Maurício: a morte em extrema miséria. Acesso: 02/08/2020 https://movimento.com/marcos-portugal-x-padre-jose-mauricio-morte-em-extrema-miserial ,2016.

CAMPOS, A. Marilia si me não amas, não me diga a verdade. Rio de Janeiro, Música Brasilis, 2017. 
CARDOSO, A. A música na Corte de D. João VI. São Paulo, Martins Fontes, 2008.

FRANÇA, E. N. Música do Brasil: Fatos, figuras e obras. Rio de Janeiro. Instituto Nacional do Livro, 1967.

FREYRE, G. Casa-Grande e senzala. 84a edição. São Paulo, Clobal, 2016. [1933]

GLASER, A. L. Raymond Williams: materialismo cultural. São Paulo, Biblioteca24horas, 2011.

HAZAN, M. C. "Raça, Nação e José Maurício Nunes Garcia". Resonancias: Revista de investigación musical, vol. 13, n. 24, pp. 23-40, 2009.

HEITOR, L. Música e músicos do Brasil. Rio de Janeiro, Editora da Casa do Estudante do Brasil, 1950.

HERTZMAN, M. A. Making Samba: a new history of race and music in Brazil. Nova lorque, Duke University, 2013.

HOLANDA, S. B. de. Raízes do Brasil. 27 a edição. São Paulo, Companhia das Letras, 2016 [1936].

MACALHÃES PINTO, A. F. Escritos de liberdade: literatos negros, racismo e cidadania no Brasil oitocentista. Campinas, Editora Unicamp, 2018.

MILCENT, F. D. Jornal de Modinhas com acompanhamento de cravo pelos milhores autores (edição em livro). Lisboa, Real Fábrica e Armazém de Música, 1820.

MATTOS, C. P. de. José Maurício Nunes Carcia: Biografia. Rio de Janeiro, Biblioteca Nacional, 1997.

MERRIAM, A. P. The Anthropology of Music. Michigan, Northwestern University, 1964.

OLIVEIRA, A. J. M. de. "Suplicando a "dispensa do defeito da cor": clero secular e estratégias de mobilidade social no Bispado do Rio de 
Janeiro - século XVIII". ENCONTRO DE HISTÓRIA ANPUH RIO, n. 13, pp. $1-8,2008$.

OLIVEIRA PINTO, T. de. "Questões de antropologia sonora”. Revista de Antropologia, v. 44, n. I, pp. $221-86,2001$.

PAZ, E. 500 canções brasileiras. Brasília, MusiMed, 2010.

QUEIROZ, E. de. O primo Bazilio: episodio domestico. Porto, Lello Irmãos, 1912 [1878].

RIBEIRO, D. O povo brasileiro: a formação e o sentido do Brasil. São Paulo, Clobal, 2015 [1995].

SANTOS, I. L. dos. Historia da África e do Brasil afrodescendente. Rio de Janeiro, Pallas, 2018.

SCHLICHTHORST, C. O Rio de Janeiro como é. Rio de Janeiro. Editora Zélio Valverde, 1943 [1824-26].

SOARES, L. C. O "povo de cam" na capital do Brasil: a escravidão urbana no Rio de Janeiro do Século XIX. Rio de Janeiro, 7Letras, 2007.

STROETER, G., MORI, E. (org.). Uma árvore da Música Brasileira. São Paulo, Sesc Ediç̃oes, 2020.

SUZUKI, M. O gênio romântico: crítica e história da filosofia em Friedrich Schlegel. São Paulo, Editora lluminuras, 1998.

TINHORÃO, J. R. Domingos Caldas Barbosa: o poeta da viola, da modinha e do lundu. São Paulo, Editora 34, 2004.

VACCARI, P. R. Padre José Maurício Nunes Carcia e o mulatismo musical: embranquecimento histórico? Revista Música da USP, São Paulo, v. 18, n. 1, pp. 170-85, 2018.

Padre José Maurício Nunes Garcia: um embranquecimento historiográfico. Revista Música em Contexto, Brasilia, v. 13, n. 2, pp. 54-70, 2019. 
"Mulatismo musical" e sua simbologia: uma revisão historiográfica do Padre José Maurício a partir da etnomusicologia. Revista Internacional em Língua Portuguesa, Lisboa, v. I, n. 37, pp. 47-72, 2020a.

Padre José Maurício Nunes Carcia e os "inventores do Brasil": a perspectiva sobre o negro dos anos 1930 e o nacionalismo em Arte. Revista Ictus, Salvador, v. 14, n. I, pp. 81 -98, $2020 b$.

\section{Sobre o autor}

Pedro Vaccari é bacharel em Canto pela Unesp, onde também concluiu seu Mestrado em Performance, sob orientação de Martha Herr. Na Alemanha estudou com o tenor Gerd Türk, e no Brasil com Neyde Thomas e o tenor Fernando Portari. Cantou em Masterclass para Kiri te Kanawa, para o tenor Luiz Tenaglia e diversas outras Masterclasses, como da Universidade de Atlanta (EUA). Recentemente teve aulas na Itália com o tenor Nicola Pamio. Sob a direção de Mauro Urona cantou diversas pocket óperas, foi bolsista do CNPa por três vezes consecutivas, e atualmente é doutorando pela Unesp, sob a orientação de Dorotea Kerr. Foi selecionado para a Bachakademie em Stuttgart na Alemanha, e desde 2008 integra o Coral Paulistano do Teatro Municipal de São Paulo. Também poeta, publicou poemas pela editora portuguesa Chiado e pela brasileira Vivara, e sua antologia poética foi indicada para publicação. Semifinalista do Concurso Os Três Tenores promovido pela Rede Record, também foi classificado para o Programa Prelúdio, da TV Cultura, onde cantou a primeira audição nacional da ópera L'esule di Roma de Donizetti. Especialista em Música brasileira, gravou CD com peças de Ronaldo Miranda, orientado pelo próprio compositor, e desenvolve pesquisa etnomusicológica sobre o Padre José Maurício Nunes Carcia. Foi banca do Congresso de Iniciação Científica da Unesp em 2012, e teve artigos publicados pela Anppom, Unirio, etc. Estudou piano com Claudio Tegg.

Recebido em 02/09/2020

Aprovado em 12/10/2020 